\title{
The Relationship between Individual and Institutional Freedom
}

\author{
Dragan Miljkovic \\ Department of Applied Economics, North Dakota State University, Fargo, ND, USA \\ Email: Dragan.Miljkovic@ndsu.edu
}

How to cite this paper: Miljkovic, D. (2018). The Relationship between Individual and Institutional Freedom. Open Journal of Political Science, 8, 81-94. https://doi.org/10.4236/ojps.2018.82007

Received: January 15, 2018

Accepted: April 5, 2018

Published: April 8, 2018

Copyright $\odot 2018$ by author and Scientific Research Publishing Inc. This work is licensed under the Creative Commons Attribution International License (CC BY 4.0).

http://creativecommons.org/licenses/by/4.0/

\begin{abstract}
We hypothesize that the institutions that are created to enable functioning of a political and economic system serve to protect that framework. In turn, these institutions increase the individual freedom. Empirical results confirm that the presence of political freedom and institutions have a significant impact on individual freedom considering all 176 countries in the sample. Economic freedom, on the other hand, has no impact on incarceration rates and, in turn, on individual freedom. The auxiliary hypotheses tested confirm that increased wealth and income inequality lead to higher incarceration rates, i.e. lesser individual freedom. This suggests that economic institutions are built in a way that disproportionally protects rights of more affluent segments of societies.
\end{abstract}

\section{Keywords}

Economic Freedom, Incarceration Rates, Income Levels and Distribution, Individual Freedom, Political Freedom

\section{Introduction}

Freedom has been a concept whose meaning preoccupied philosophers for centuries, yet no consensus exists on that matter to date. Moreover, the complex relationship between individual freedom and political and, more recently, economic freedom and, in turn, related institutions has only further complicated the matter. Definitions of freedom used in this paper are only a reflection of the authors' own understanding and preference rather than a normative statement of how freedom should be understood.

In defining individual freedom, we follow Kant's view. He calls individual freedom the genuine freedom and defines it as the right of individuals to be independent of the choices of others (Kant, 1996). Moreover, Kant calls freedom 
the innate right of humanity, the "only original right belonging to every man in virtue of his humanity" (Kant, p. 237). But how can so defined genuine freedom exist in the real world? Kant goes on to suggest that such independence is possible only if legal and political orders are established and well-functioning as that helps govern and enforce the limits of such relations (Botterell, 2011). Such order is conditio sine qua non for one to be in full control of her/his own being. Without it, one is likely to be an object serving someone else's purposes and actions, and just reacting to them. Such political force is the state's innate right to make the interactions among citizen within given group (e.g., society) plausible and functional. One of the most vocal and recognized modern day supporters of Kant's view on genuine freedom and its relationship with political force is Ripstein (2010). He goes on to affirm that the relation between (political) force and freedom is therefore a necessary one.

Ripstein recognizes that Kantian's genuine freedom and the acquisitions of private rights within such system is possible only if a rightful condition exists. Such a condition is one, "... in which a legislative power makes clear the scope and extent of one's acquired rights; in which an executive power enforces the boundaries of those rights; and in which a judiciary resolves disputes about unclear cases" (Botterell, 2011: p. 457), i.e., a civil society. Hence political freedom via its judicial and legal system mechanism is the necessary condition for individual freedom to exist in practice.

When economic freedom is introduced, the discussion about individual freedom and its relationship with economic freedom becomes much more complicated. Economists often use forcefully in their discourses the rhetoric of freedom in defending the market mechanism. Following Friedman and Friedman (1990), market system makes people free to choose. However, it is well known that that the economic theory of market allocation is firmly linked with the welfare centered normative framework (e.g., Samuelson, 1947; Debreu, 1959; Arrow, 1963; Hicks, 1975). In other words, the success and failures of competitive markets are judged entirely by achievements of individual welfare, be it by utilizing utility-based Pareto optimality or some different criterion, rather than by accomplishments in promoting individual freedom. In an array of contributions, Sen (e.g., 1988, 1991, 1992, 1993) argued how "market freedom" may lead to an increase in economic efficiency, yet it is uncertain, at best, that it leads to an increase in individual freedom. More recent work by Berggren and Nilsson (2013) analyzes specific aspects of the economic freedom impact on individual wellbeing via its impact on tolerance towards distinct groups. Cross-sectional regression analysis of up to 69 countries reveals that economic freedom is positively related to tolerance towards homosexuals, especially in the longer run, while tolerance towards people of a different race and a willingness to teach kids tolerance are not strongly affected by how free markets are. Stable monetary policy and outcomes are the area of economic freedom most consistently associated with greater tolerance, but the quality of the legal system seems to matter as well. 
And even long before Sen, Hayek (1960) recognized the fundamental importance of individual freedom in the context of a society overall:

".. the importance of our being free to do a particular thing has nothing to do with the question of whether we or the majority are ever likely to make use of that possibility... It might be even said that the less likely the opportunity to make use of freedom to do a particular thing, the more precious it will be for society as a whole. The less likely the opportunity, the more serious will it be to miss it when arises, for the experience it offers will be nearly unique (Hayek 1960: p. 31).

Indeed, we see that Hayek's idea of individual freedom is a concept not unlike one defined previously by Kant. Yet, economics as a discipline drifted away from that notion towards economic freedom, as previously elaborated, narrowly welfare and economic efficiency based notions.

The objective of this paper is to establish the links between individual freedom on one side, and political and economic freedom on the other side. It is hypothesized here that the institutions that are created to enable functioning of a political and economic system serve to protect that framework. This view is consistent with North's hypothesis that institutions (both political and economic) are not (intrinsically) efficient and that in real world ideas and ideologies play a significant role in individual choices and transactions (North, 2016). In turn, these institutions increase the individual freedom, as Kant suggested they would. Thus, every individual behavior which is at odds with instituted political and economic system is likely to be sanctioned by that system. In other words, more institutional freedom, be it political or economic, is likely to increase individual freedoms via the legal, political and economic measures introduced by the political and economic system.

The paper is organized as follows. The concepts of individual freedom and political and economic freedom are further developed and links among them developed/hypothesized in second section. Data used in the empirical analysis along with the econometric model are presented in the third section. Next, empirical results are analyzed, and robustness tests conducted. The paper ends with the conclusions and the implications of the findings.

\section{Concepts of Freedom}

Defining individual freedom à la Kant as the right of individuals to be independent of the choices of others is a great sounding philosophical concept and ideal. However, it is abstracted from reality as humans do not live in a vacuum, but function as the social beings. And, these societies operate within various political and economic frameworks, e.g., democracy, monarchy, dictatorship, centrally planned economy, market economy, just to name a few. It is commonly assumed that certain societies and systems are freer than others, i.e. that the causality flows from the type of political and economic system to freedom. An example would be that there is more freedom in democracy than in a dictatorship (e.g., 
Cheibub et al., 2010; McFaul, 2002; Olson, 1993). However, these assertions are hard to prove if one is to define the freedom as the genuine or individual freedom rather than as the political or economic freedom. A key question that often remains unaddressed is how do we measure individual freedom? One plausible measure would be the incarceration rate in a nation as it is defined as the prison population per 100,000 people in the national population (The World Prison Brief, 2016). This measure provides the share of population in a nation that has no rights independent of the choices of others; indeed, they barely have any rights at all.

The incarceration rates among the population in a nation is sometimes considered as one of the indicators of development (e.g., Ruddell, 2005; Jacobs \& Kleban, 2003). Yet we see that many nations that are considered developed based on income per capita, life expectancy, child mortality and some other criteria have very high incarceration rates, relative to many less developed countries. Mauer (2003) and Blumstein and Beck (1999), among others, study incarceration rates in the U.S. and other developed nations. The incarceration rates in the U.S. are highest among industrialized nations. U.S. incarcerates more and for longer for similar crimes compared to other nations. Trends of racial disparity are common throughout developed countries; minority groups in all of these countries tend to have much higher imprisonment rates from the average. It is believed that a strong economy, changes in the age structure of a community, less drug use, and other social factors can lead to lower incarceration rates. However, their conclusion about strong economy leading to a lesser incarceration rate flies directly in the face of the fact that the U.S. has the highest incarceration rates among all developed countries. In a more recent study study, Miller (2011) also examined the reasons for high incarceration rates in industrialized countries. Level of corruption in the government was one of the factors examined. It was found that high corruption was correlated with high rates of drug crime. Countries with low and moderate levels of corruption have more violent and property crimes. Highly corrupt countries have extremely high correlations between poverty, unemployment, and incarceration rates. Countries with low corruption also have an extremely high correlation between incarceration rate and immigrant population.

Indeed, political and economic freedom can be understood in many different ways. Here is how are political and economic freedom considered in this paper. Political freedom is the measure of the political rights of a country. Political rights are determined by three primary categories: electoral process, political pluralism and participation, and functioning of government. The electoral process factor is determined by the freedom and fairness of the election process for government leaders and legislative representatives as well as the fairness of electoral laws and framework. Political pluralism and participation is based on the right of citizens to form political parties, the opportunity for opposing parties to grow through elections, the ability of citizens to make their own political 
choices free from dominating parties, and opportunities granted to minorities. Function of government is measured by the degree to which elected officials determine policy, the amount of corruption present, and the openness and transparency of the government.

Economic freedom, in this paper, is based on four primary factors: rule of law, government size, regulatory efficiency, and market openness. Rule of law is based on property rights and freedom from corruption. Government size is measured by fiscal freedom and government spending. Regulatory efficiency is assessed by measurements of business freedom, labor freedom, and monetary freedom. Market openness is determined by trade freedom, investment freedom, investment restrictions, and financial freedom.

Most developed nations enjoy high levels of political and economic freedom. By transitivity, one could be tempted to believe how that should imply a high level of individual or genuine freedom reflected in low incarceration rates. However, we have already discussed some influential research and simple facts that many developed nations do not have low incarceration rates, and in turn high level of the individual freedoms. A completely different idea is proposed in this paper. We propose that concepts of political and economic freedom are only a reflection of the set of prevailing normative standards how societal institutions should be. Strong enforcing of such values, even if they explicitly claim to promote political and economic freedom, are likely to limit individual freedom considerably. Moreover, individual behaviors deviating from a large set of strict norms are likely to be punished by that very society which promotes all of these institutional freedoms. In turn, the incarceration rates are likely to be high in such societies. Simply said, we propose that high levels of institutional freedoms, as reflected via political and economic freedoms, have negative correlations with individual freedoms proxied by incarceration rates. We empirically test this hypothesis using the data from 176 countries. We also test a number of ancillary hypotheses such as the relationship between the level of income per capita and income distribution with both individual and institutional freedoms. Finally, we add many more variables to test for the robustness of our empirical model and results.

\section{Data and Model}

\subsection{Data}

A cross sectional data set is used with a total of 176 observations, each representing a separate country. Incarceration rate is defined as the prison population per 100,000 people in the national population. Data was retrieved from the International Centre for Prison Studies, World Prison Brief. The data reflects the incarceration rates as of July, 2013. The average for the entire sample equals 166 incarcerated people per 100,000 people. Quantitative (numerical) variables included are income per capita, Gini coefficient, economic freedom index, political freedom index, and population density. Income per capita is measured in 
constant 2005 U.S. dollars, and the data is collected from the World Bank. The year 2012 is used for the vast majority of countries, but most recent years available prior to 2012 are used in a very few instances in which 2012 was not available. Average GDP per capita for the 176 countries considered is USD 10,472. Same source is used for Gini coefficient variable, for year 2013 or, if not available, the most recent year before 2013 for which the measure was published. Average value of the Gini coefficient is 40. Data for the population density, measured as the number of people per square kilometer, are collected from the web pages for each of the countries included in the analysis.

The political freedom rating of 2013 is used, as is defined by Freedom House. As defined in the previous section, the rating measures the political rights of a country. The rating ranges from 1 to 7 , with 1 representing the most political freedom. More specifically, countries and territories with a rating of 1 enjoy a wide range of political rights, including free and fair elections. Candidates who are elected actually rule, political parties are competitive, the opposition plays an important role and enjoys real power, and the interests of minority groups are well represented in politics and government. Countries and territories with a rating of 2 have slightly weaker political rights than those with a rating of 1 because of such factors as political corruption, limits on the functioning of political parties and opposition groups, and foreign or military influence on politics. Countries and territories with a rating of 3, 4, or 5 either moderately protect almost all political rights or strongly protect some political rights while neglecting others. The same factors that undermine freedom in countries with a rating of 2 may also weaken political rights in those with a rating of 3,4 , or 5 , but to a greater extent at each successive rating. Countries and territories with a rating of 6 have very restricted political rights. They are ruled by one-party or military dictatorships, religious hierarchies, or autocrats. They may allow a few political rights, such as some representation or autonomy for minority groups, and a few are traditional monarchies that tolerate political discussion and accept public petitions. Finally, countries and territories with a rating of 7 have few or no political rights because of severe government oppression, sometimes in combination with civil war. They may also lack an authoritative and functioning central government and suffer from extreme violence or rule by regional warlords. Average value for the political freedom index for the countries in the sample is 3.31 .

The 2013 index of economic freedom is used, and is collected from the Heritage Foundation. The index is on a scale of 1 to 100, with 100 representing the most economic freedom. As mentioned previously, it is based on four primary factors: rule of law, government size, regulatory efficiency, and market openness. To provide as comprehensive a picture as possible of conditions in these four categories, the economic index of freedom measures 10 specific components of economic freedom, each of which is graded on a scale from 0 to 100 . Scores on these 10 components of economic freedom, which are calculated from a number of sub-variables, are equally weighted and averaged to produce an overall eco- 
nomic freedom score for each economy. Average value of the economic freedom index for all 176 countries is $59.92 .{ }^{1}$

A few qualitative variables are also introduced in the model, mostly to test for the robustness of the key results of interest. Dummy variables are used in the study to signify national languages and religions. English, French, Portuguese, Spanish, German, Dutch, and Arabic language dummy variables are used with the default being any other language. The official languages are used for each country. If no official languages exist, the national languages are used, and further if there are no national languages then the most widely spoken language in the country is considered. Several countries do indeed have multiple official or national languages. Information is gathered from the official web pages of each individual country. Information on national religions is collected from the Pew Research Religion \& Public Life Project. Religions are categorized as Christian, Muslim, Unaffiliated, Hindu, Buddhist, and Jewish, with other as the default. The dummy variable simply signifies which denomination has the largest following in a given country. ${ }^{2}$

\subsection{Econometric Model}

A system of three equations is specified, with endogenous variables being the incarceration rate, political freedom index, and economic freedom index, respectively. In this case, one cannot say with certainty that the left-hand side variables are endogenous, so a two-stage least squares (2SLS) estimation could be appropriate. A Hausman specification test has been conducted to test for simultaneity (Pindyck \& Rubinfeld, 1997). Its results suggested that there is no simultaneity. Thus, ordinary least squares (OLS) should generate efficient and consistent parameter estimators. Moreover, given the cross-sectional nature of the data, the problem of heteroscedasticity is likely to arise. To correct that problem, we follow White (1980) who derived a heteroskedasticity consistent covariance matrix estimator which provides consistent estimates of the coefficient covariances in the presence of conditional heteroskedasticity of unknown form. When appropriate, the variables are in log form so the estimated coefficients can be interpreted as elasticities. The three estimated equations are as follows:

$$
\begin{aligned}
\ln I R_{i}= & \beta_{1}+\beta_{2} P I_{i}+\beta_{3} E F I_{i}+\beta_{4} \ln \text { GDP } / \text { Cap }_{i}+\beta_{5} \text { Gini }_{i} \\
& +\beta_{6} \ln \text { PDens }_{i}+\beta_{j} D_{j}+\varepsilon_{1, i} \\
\text { PFI }_{i}= & \alpha_{1}+\alpha_{2} \ln I R_{i}+\alpha_{3} E F I_{i}+\alpha_{4} \ln \text { GDP } / \text { Cap }_{i}+\alpha_{5} \text { Gini }_{i} \\
& +\alpha_{6} \ln \text { PDens }_{i}+\alpha_{j} D_{j}+\varepsilon_{2, i} \\
E_{F}= & \gamma_{1}+\gamma_{2} \ln I R_{i}+\gamma_{3} \text { PFI }_{i}+\gamma_{4} \ln \text { GDP } / \text { Cap }_{i}+\gamma_{5} \text { Gini }_{i} \\
& +\gamma_{6} \ln \text { PDens }_{i}+\gamma_{j} D_{j}+\varepsilon_{3, i}
\end{aligned}
$$

Notation for the variables is as follows. $I R$ stands for incarceration rates, while $P F I$ and $E F I$ are political and economic freedom indices, respectively. GDP/Cap denotes income per capita, Gini stands for Gini coefficient, while PDens stands 
for population density. Finally, $D$ denotes various dummy variables for different religions or languages. Subscript $i$ is for the cross-section of countries included in the study.

\section{Results}

The regression model results can be seen in Table 1. Given the large number of

Table 1. Regression Results.

\begin{tabular}{|c|c|c|c|}
\hline \multirow[t]{2}{*}{ Independent Variables } & \multicolumn{3}{|c|}{ Dependent Variables } \\
\hline & $\ln I R_{i}$ & $\mathrm{PFI}_{i}$ & $E F I_{i}$ \\
\hline \multirow[t]{2}{*}{$\ln I R_{i}$} & & $0.9541^{* * *}$ & 1.1632 \\
\hline & & $(0.000)$ & $(0.226)$ \\
\hline \multirow[t]{2}{*}{$P F I_{i}$} & $0.1341^{* * *}$ & & $-0.8217^{\star \star}$ \\
\hline & $(0.000)$ & & $(0.049)$ \\
\hline \multirow[t]{2}{*}{$E F I_{i}$} & 0.0099 & $-0.0332^{* *}$ & \\
\hline & $(0.138)$ & $(0.040)$ & \\
\hline \multirow[t]{2}{*}{$\ln G D P / C_{a p}$} & $0.2505^{* * *}$ & -0.0959 & $5.1938^{* * *}$ \\
\hline & $(0.000)$ & $(0.424)$ & $(0.000)$ \\
\hline \multirow[t]{2}{*}{ Gini $_{\mathrm{i}}$} & $0.0233^{* * *}$ & $0.0584^{\star * \star}$ & $0.1291^{\star}$ \\
\hline & $(0.000)$ & $(0.000)$ & $(0.084)$ \\
\hline \multirow[t]{2}{*}{$D_{\text {Christ }}$} & $0.3758^{\star \star}$ & & $-3.7528^{\star *}$ \\
\hline & $(0.013)$ & & $(0.021)$ \\
\hline \multirow[t]{2}{*}{$D_{\text {Jew }}$} & $0.5727^{* * *}$ & & $-7.2248^{\star * *}$ \\
\hline & $(0.001)$ & & $(0.000)$ \\
\hline \multirow[t]{2}{*}{$D_{\text {Bud }}$} & $0.4600^{*}$ & & $4.1529^{\star}$ \\
\hline & $(0.067)$ & & $(0.063)$ \\
\hline \multirow[t]{2}{*}{$D_{M u s}$} & & $2.1466^{\star * *}$ & \\
\hline & & $(0.000)$ & \\
\hline \multirow[t]{2}{*}{$D_{\text {French }}$} & $0.5018^{* * *}$ & $1.0664^{* * *}$ & \\
\hline & $(0.002)$ & $(0.006)$ & \\
\hline \multirow[t]{2}{*}{$D_{\text {English }}$} & & $-0.8457^{\star * *}$ & $2.9631^{\star}$ \\
\hline & & $(0.014)$ & $(0.085)$ \\
\hline \multirow[t]{2}{*}{$D_{\text {Spanish }}$} & & $-0.8402^{*}$ & \\
\hline & & $(0.073)$ & \\
\hline \multirow[t]{2}{*}{$D_{\text {German }}$} & & & $3.3206^{*}$ \\
\hline & & & $(0.100)$ \\
\hline R-squared & 0.539 & 0.482 & 0.513 \\
\hline Adjusted R-squared & 0.502 & 0.452 & 0.483 \\
\hline
\end{tabular}

Numbers in parentheses are p-values. ${ }^{* *},{ }^{* *}$, and ${ }^{*}$ denote statistical significance at $1 \%, 5 \%$, and $10 \%$, respectively. 
variables, only statistically significant coefficient in each of the equations are reported in addition to the three freedom variables. The fit of each individual model, as measured by the R-squared, is in the range from 0.48 to 0.54 , which is fairly god considering the cross-sectional nature of the data. Moreover, the adjusted R-squared in all three equations is very close to the R-squared, indicating relatively good model specification.

The main relationship of interest here is one among the three freedom variables, and the results are rather interesting and instructive. First, we need to recall that political freedom index is constructed in such a way that lower political freedom rating implies higher level of political freedom. Therefore, positive coefficients/correlations between individual freedom, as measured by the incarceration rate, and political freedom rating, in both incarceration rates and political freedom equations, indicate that more political freedom implies more individual freedom, and the vice versa. Higher level of political freedom measured by one political freedom index point decrease leads to a decrease in incarceration rates by 0.134 percent; or, less political freedom measured by one political freedom index point increase leads to an increase in incarceration rates by 0.134 percent. Similarly, one percent increase in incarceration rate leads to 0.95 points increase in political freedom index thus indicating decreasing levels of political freedom. This relationship indicates that individual freedom in a way is politically motivated concept, and not an intrinsic right by every human, in Kant's sense of the word. Political freedom infrastructure is therefore condition sine qua non for existence of individual freedom.

Incarceration rates, and in turn individual freedom, and economic freedom, as measured by the economic freedom index, are not correlated at any of the standard level of significance. In other words, more economic freedom in a country has no impact on individual freedom at all, and the vice versa. An interesting corollary to this finding is that creating an economic system conducive to commerce and vibrant economy does not imply lower crime and incarceration rates. Indeed, incarceration rates and the nature of economic system in a country are unrelated.

The relationship between political and economic freedom, as the two aspects of institutional freedom, is also tested, as an auxiliary hypothesis. Please notice that this relationship has been researched before, and most recent review can be found in Jäger (2017). Our model results are as expected: more economic (political) freedom leads to more political (economic) freedom. What is interesting about this relationship is relatively small size of this correlation. For instance, an increase in the economic freedom index by one point (measured on a scale 1 100 ), leads to a decrease in political freedom index by 0.0332 (measured on a scale 1 - 7); indeed, a very modest improvement in political freedom of the countries in consideration. This relationship implies, however modest, coordination between economic and political freedom institutional arrangements.

Especially interesting, and somewhat unexpected, results are regarding the 
impact of the GDP/capita on individual and institutional freedom. One result that is according with our expectation is positive correlation between $\mathrm{GDP} /$ capita and economic freedom: there is a large increase in economic freedom index for every percent increase in GDP/capita. Indeed, wealthier societies are more likely to provide more freedom to all economic subjects, and create economic institutions consistent with free market economies concept. On the other hand, GDP/capita does not have any impact on political freedom, i.e. wealthier societies are equally likely to be oppressive as those with much lower incomes. This may not be completely unexpected as some of the countries with very high GDP/capita have very restricted political rights as they are ruled by one-party or military dictatorships, religious hierarchies, or autocrats, and in case of some of the traditional monarchies, they do not tolerate political discussion and accept public petitions.

Most interesting, however, is the result indicating positive correlation between GDP/capita and incarceration rates: one percent increase in per capita income leads to an increase of 0.25 percent in incarceration rate. Thus, wealthier societies are more likely to have more individuals incarcerated. There could be a few competing explanations for this outcome. First, wealthier countries are more likely to have more developed system of prisons and thus relatively larger imprisonment capacity. Alternatively, wealthier nations could be more likely to protect the wealth of the wealthiest segment of the population thus adjusting legal system towards protection of the status quo and in turn their wealth. This explanation would also be consistent with an increase in income inequality, as measured by Gini coefficient, leading to an increase in incarceration rates and in turn lowering individual freedom. Consistent with the above result, an increase in income inequality further leads to less political freedom. Finally, growing income inequality leads not only to more individuals in prisons and lesser political freedom, but also to an increase of economic freedom, i.e. increasing income inequality is consistent with more efficient economic systems. This all may mean that the wealthiest segment of the population is likely to create the economic, political and legal system that will serve their interest as the divide between rich and poor increases. Moreover, it also tells us that adopted current definitions of economic and political freedom are based on the notions of efficiency rather than equality.

Religion prevalence dummies also provide some interesting insight into the nature of individual and institutional freedom limits world-wide. Increased incarceration rates are more likely in some predominantly religious states relative to predominantly secular states. Predominantly Christian, Buddhist and Jewish countries have relatively largest incarceration rates and in turn least levels of individual freedom. It is possible that legal systems of these countries are heavily impacted by more rigid religious creeds thus leading to a relatively large incarceration rates and low levels of individual freedom in Kant's sense. Predominantly Muslim countries, one could say according to expectations, are most 
likely to stifle the political freedom as in many of Muslim countries legal system is based on, at least in part, religious Sharia law rather than secular laws. Most surprising aspect of the results regarding the religion impacts on freedoms is observed when Christianity and Judaism suppress economic freedom. Indeed, one could argue that most western countries are Christian but also free market economies with economic institutions set up accordingly; the results of the model, however, state the opposite.

When considering language spoken in the country, that has to do with cultural including colonial heritage. French speaking countries have disproportionally more incarcerated people and in turn lesser level of individual freedom tan the rest of the world. Consistent with that is a lesser level of political freedom in French speaking countries. This should not come as a surprise as a large number of French speaking countries are former French colonies in Africa and Asia with non-democratic regimes in charge. English speaking countries, on the other hand, are more likely than all other countries to have high levels of economic freedom. This also does not come as a surprise as many new world developed countries are English speaking, are among the largest economies in the world, and serve as the model for free market economic system. Finally, English and Spanish speaking countries both have more political freedom than the rest of the world.

\section{Summary and Conclusion}

Humans are social beings, and as such are bound to always be, directly or indirectly, interacting with others. Yet, the notion of individual or genuine freedom remains single, most important for humans in all historical and contemporary societies. Kant calls individual freedom the genuine freedom and defines it as the right of individuals to be independent of the choices of others. This implies a contradiction of a sort as humans are in constant need of both individual independence and freedom, and of living within a society broadly understood as a more or less ordered community. We empirically examine, for a sample of 176 countries, the relationships between individual freedom, measured by the incarceration rates in a society, and institutional freedom, proxied by political and economic freedom indices.

Results, in part, confirm the Kant hypothesis that genuine (individual) freedom is possible to be achieved only if proper social institutions are developed and create an environment conducive to the existence of the genuine freedom. The presence of political freedom and institutions have a significant impact on the presence of individual freedom considering all of 176 countries. This relationship goes both ways as individual freedom implies higher levels of political freedom too. Economic freedom, on the other hand, has no impact on incarceration rates and, in turn, on individual freedom. The auxiliary hypotheses tested confirm that increased wealth and income inequality lead to higher incarceration rates, i.e. lesser individual freedom. This is somewhat troubling as it seems 
that social, economic, institutions are built in a way that protects rights of more affluent segments of societies more than the rights of an average person. This result may not come as a surprise to some economists (e.g., Sen, 1988, 1991, 1992, 1993) who argue that welfare-based measures of development and growth are not likely to account for the impacts of increased economic efficiency on the state of genuine freedoms among the individuals in modern global societies. In other words, Sen has argued that we often confuse the means of obtaining development via institutional (economic) freedom such as increased GDP or per capita income obscure the fact that the goal of a societal development is the freedoms themselves (e.g., Reuss, 2003). Our results are consistent with this hypothesis. Finally, we conclude, based on our 176-country samples that global institutional freedom increase, in neoliberal sense, does not necessarily lead to increases in genuine freedom, a hypothesis previously established by the Left critics of neoliberal globalization (e.g., DeMartino, 2000; Diskin, 2003).

An important limitation of the study is its cross-sectional, static nature. Indeed, the results would be more powerful if the data for all freedom variables and for all (or most) countries included in the study was available over an extended period. That would enable us to discuss the dynamic relationship of individual and institutional freedoms, i.e. a change, if any, occurring over time in these relationships. Unfortunately, data for some of the variables are not available for many of the countries in our sample. While using smaller sample would enable us to analyze dynamic relationship of individual and institutional freedoms, the tradeoff in losing too much information due to small sample size and by introducing possible bias, as countries with data available are mostly western, developed nations, is too large to justify such an endeavor. One must be careful to recognize, however, that creation of political and economic institutions is a process that takes long time; thus, it is unlikely to observe major discrete jumps in any of the indicators of freedom over short periods. Likely, a historical study of these changes encompassing several decades would be best suited for a study aiming to achieve such goals.

\section{References}

Arrow, K. J. (1963). Social Choice and Individual Values (No. 12). Yale: Yale University Press.

Berggren, N., \& Nilsson, T. (2013). Does Economic Freedom Foster Tolerance? Kyklos, 66, 177-207.

Blumstein, A., \& Beck, A. J. (1999). Population Growth in US Prisons, 1980-1996. Crime and Justice, 26, 17-61. https://doi.org/10.1086/449294

Botterell, A. (2011). Review of Arthur Ripstein, Force and Freedom. https://philpapers.org/archive/BOTROA

Cheibub, J. A., Gandhi, J., \& Vreeland, J. R. (2010). Democracy and Dictatorship Revisited. Public Choice, 143, 67-101. https://doi.org/10.1007/s11127-009-9491-2

Debreu, G. (1959). Theory of Value: An Axiomatic Analysis of Economic Equilibrium (No. 17). Yale: Yale University Press. 
DeMartino, G. (2000). Global Economy, Global Justice. London and New York: Routledge.

Diskin, J. (2003). Global Economy, Global Justice. Review of Radical Political Economics, 35, 201-204. https://doi.org/10.1177/0486613403035002010

Friedman, M., \& Friedman, R. (1990). Free to Choose: A Personal Statement. Boston, Massachusetts: Houghton Mifflin Harcourt.

Hayek, F. A. (1960). The Constitution of Liberty. Chicago: The University of Chicago.

Hicks, J. R. (1975). Value and Capital: An Inquiry into Some Fundamental Principles of Economic Theory. Oxford: Oxford University Press.

Jacobs, D., \& Kleban, R. (2003). Political Institutions, Minorities, and Punishment: A Pooled Cross-National Analysis of Imprisonment Rates. Social Forces, 82, 725-755. https://doi.org/10.1353/sof.2004.0013

Jäger, K. (2017). Economic Freedom in the Early 21st Century: Government Ideology Still Matters. Kyklos, 70, 256-277. https://doi.org/10.1111/kykl.12137

Kant, I. (1996). Kant: The Metaphysics of Morals. Cambridge: Cambridge University Press. https://doi.org/10.1017/CBO9780511809644

Mauer, M. (2003). Comparative International Rates of Incarceration: An Examination of Causes and Trends. Presented to the US Commission on Civil Rights (pp. 1-16). The Sentencing Project.

McFaul, M. (2002). The Fourth Wave of Democracy and Dictatorship: Non-Cooperative Transitions in the Post-Communist World. World Politics, 54, 212-244. https://doi.org/10.1353/wp.2002.0004

Miller, L. (2011). Explaining Variation in Incarceration Rates. Asheville, NC: University of North Carolina.

North, D. C. (2016). Institutions and Economic Theory. The American Economist, 61, 72-76. https://doi.org/10.1177/0569434516630194

Olson, M. (1993). Dictatorship, Democracy, and Development. American Political Science Review, 87, 567-576. https://doi.org/10.2307/2938736

Pindyck, R. S., \& Rubinfeld, D. L. (1997). Econometric Models and Economic Forecasts (4th ed.). New York, NY: McGraw-Hill.

Reuss, A. (2003). Development as Freedom. Review of Radical Political Economics, 35, 189-191. https://doi.org/10.1177/0486613403035002006

Ripstein, A. (2010). Force and Freedom. Cambridge, MA: Harvard University Press.

Ruddell, R. (2005). Social Disruption, State Priorities, and Minority Threat: A Cross-National Study of Imprisonment. Punishment \& Society, 7, 7-28.

https://doi.org/10.1177/1462474505048131

Samuelson, P. A. (1947). Foundations of Economic Analysis. Samuelson Foundations of Economic Analysis.

Sen, A. (1988). Freedom of Choice: Concept and Content. European Economic Review, 32, 269-294. https://doi.org/10.1016/0014-2921(88)90173-0

Sen, A. (1991). Welfare, Preference and Freedom. Journal of Econometrics, 50, 15-29. https://doi.org/10.1016/0304-4076(91)90087-T

Sen, A. (1992). Minimal Liberty. Economica, 59, 139-159. https://doi.org/10.2307/2554743

Sen, A. (1993). Markets and Freedoms: Achievements and Limitations of the Market 
Mechanism in Promoting Individual Freedoms. Oxford Economic Papers, 45, 519-541. https://doi.org/10.1093/oxfordjournals.oep.a042106

The World Prison Brief (2016). http://www.prisonstudies.org

White, H. (1980). A Heteroskedasticity-Consistent Covariance Matrix Estimator and a Direct Test for Heteroskedasticity. Econometrica, 48, 817-838.

https://doi.org/10.2307/1912934 